\title{
Three-dimensional cell culture: A powerful tool in tumor research and drug discovery (Review)
}

\author{
DONGLAI LV, ZONGTAO HU, LIN LU, HUSHENG LU and XIULI XU
}

Department of Clinical Oncology, The 105 Hospital of The People's Liberation Army, Hefei, Anhui 230031, P.R. China

Received September 24, 2016; Accepted July 27, 2017

DOI: $10.3892 / \mathrm{ol} .2017 .7134$

\begin{abstract}
In previous years, three-dimensional (3D) cell culture technology has become a focus of research in tumor cell biology, using a variety of methods and materials to mimic the in vivo microenvironment of cultured tumor cells ex vivo. These 3D tumor cells have demonstrated numerous different characteristics compared with traditional two-dimensional (2D) culture. 3D cell culture provides a useful platform for further identifying the biological characteristics of tumor cells, particularly in the drug sensitivity area of the key points of translational medicine. It promises to be a bridge between traditional 2D culture and animal experiments, and is of great importance for further research in the field of tumor biology. In the present review, previous 3D cell culture applications, focusing on anti-tumor drug susceptibility testing, are summarized.
\end{abstract}

\section{Contents}

1. Introduction

2. Current preclinical tumor models

3. The methods of 3D cell culture

4. Future trends and conclusions

\section{Introduction}

As one of the basic techniques utilized to study tumor cell biology, the continual development of tumor cell culture techniques is vital. Traditional cell culture methods use a two-dimensional (2D) monolayer. With continuous improvements being made, this method has become a standard technology in life sciences at present. However, due to the inherent flaws of traditional 2D culture, it fails to correctly

Correspondence to: Dr Donglai Lv, Department of Clinical Oncology, The 105 Hospital of The People's Liberation Army, 424 Changjiang West Road, Hefei, Anhui 230031, P.R. China

E-mail:1vxunhuan@163.com

Key words: three-dimensional culture, cell biology, tumor cells, drug discovery imitate the architecture and microenvironments of in vivo, which makes 2D-cultured cells different from cells growing in vivo in terms of morphology, proliferation, cell-cell and cell-matrix inter-connections, signal transduction, differentiation and other aspects $(1,2)$. In order to improve these simulations of cell microenvironments in vivo, 3D culture has become the next frontier of cell biology research.

As the intersection between tumor cell biology and tissue engineering, 3D in vitro tumor models simulate the in vivo physiological microenvironment, and may be useful at the pre-clinical development stage to identify potentially successful prototypes and eliminate failures at an early stage. This means that it has potential to bridge the gap between traditional monolayer cell culture and tumor cytology experiments in vivo. Therefore, an increasing number of tumor biologists have begun to emphasize the importance of 3D tumor cell culture (3). Subsequently, the advent of 3D culture has seen rapid advancement in the past few decades, as evidenced by the increasing number of studies in this area $(4,5)$, including preclinical drug screening, cancer stem cell maintenance and differentiation, signal abnormal transduction and other aspects (6-8). For example, compared with 2D monolayer cultures, cells in 3D culture generally exhibit a reduced sensitivity to certain chemotherapeutic agents (9). These results and the exponentially increasing number of studies surrounding this topic convey the importance of 3D tumor cell culture, one of the primary reasons for the present review.

Thus, in the present review, the current preclinical models in cancer research are briefly described in order to promote understanding of the necessity of novel cell culture system. In addition to this, the advantages and challenges of $3 \mathrm{D}$ in vitro tumor models are discussed in terms of a mechanistic understanding of tumor cell physiology and in therapeutic evaluations of anti-tumor drug discovery.

\section{Current preclinical tumor models}

At present, in vitro anti-tumor drugs tests are mainly performed by detecting the reaction of tumor cells in a 2D monolayer culture dish. It is estimated that $>80 \%$ of cancer biologists still rely on $2 \mathrm{D}$ culture techniques to obtain results prior to in vivo testing because of its convenience (10). However, in clinical trials, it has become apparent that effective drugs in in vitro experiments have no or weak efficacy in real patients with tumors (11). This phenomenon, at least 
partially, has been attributed to the fact that cells grown in 2D culture lack the complex 3D tissue architecture and cell-cell or cell-extracellular matrix (ECM) interactions which exist in the body (12). These models therefore fail to fully reflect the pathophysiology of tumor cells, and the real level of resistance to radiation or drugs in the in vivo niche $(6,13)$. For example, hepatic cancer cells in 3D culture may tolerate drug treatment, similar to the resistance characteristics of solid tumors in vivo (14). Breast cancer MCF-7 cells in 3D scaffolds demonstrated a stronger resistance to tamoxifen in endocrine therapy than those in monolayer culture (7). Additionally, drug resistance induced by cancer stem cells (CSCs) has received substantial attention in previous decades. However, traditional 2D culture fails to provide an adequate CSC enrichment culture (6). These studies suggest that the microenvironment of tumor cells may notably alter the susceptibility of cancer cell drugs. Traditional 2D culture should, therefore, be subject to further development.

Animal models are an important tool for tumor research. Animal model testing is primarily conducted to monitor drug bioavailability, therapeutic efficacy and dose-limiting toxicity (15). Any novel drugs must undergo preclinical testing in animal models prior to human clinical trials. However there remain a number of issues with these models, including higher costs, species differences, limited availability and feasibility (16). Furthermore, ethical issues in relation to the use of animals in tumor research are highly controversial. The first guideline of the animal model is that animals should be replaced with other methods wherever possible (17). Therefore, novel in vitro cell culture models are encouraged by the majority of funding agencies (4), in order to reduce the number of animals used in tumor research and drug evaluation.

To resolve these issues, 3D tumor cell culture methods have been developed where the culture environment takes into account the spatial organization and ECM of the cell. The common goal for these methods is to restructure a biomimetic 3D multicellular tumor model, which may bridge the gap between the conventional $2 \mathrm{D}$ in vitro and the animal testing models. Tumor cells in 3D models have physiological properties similar to those in vivo (5). Thus, 3D culture may be a powerful tool in tumor and relevant drug research. Marked advances have been made in the basic development of 3D tumor models so far, and prominent studies using 3D tumor cell models to simulate the tumor microenvironment or assess drug delivery in the past 5 years are summarized in Table I $(6,8,18-35)$. Considering the advantages of 3D tumor models, the present review provides an overview of the methods and techniques successfully devised for practicing 3D tumor cell culture.

\section{The methods of $3 D$ cell culture}

Multicellular tumor spheroids (MCTS). MCTS are aggregates of cancer cells grown in suspension or embedded in gels using $3 \mathrm{D}$ culture methods. This model partly recapitulates in vivo tumor microenvironments (36). For example, larger MCTS (critical size, $400 \mu \mathrm{m}$ ) sustain oxygen and nutrient gradients that often result in the formation of a necrotic core similar to those in poorly vascularized tumors (37). There are several different methods used to create MCTS models (Fig. 1), each with their distinct advantages and disadvantages.
Suspension culture. The suspension culture method was invented to isolate and culture neural stem cells from rat striatal cells in 1970s (38). Subsequently it became a widely used 3D cell culture method. The main features of this method are a serum-free and artificially low adhesion cell growth microenvironment (Fig. 1A). Specifically, the culture medium has no serum but contains a high concentration of growth factors, which are differ slightly between cell lines. For example, glioma suspension MCTS medium contains Dulbecco's modified Eagle's medium, Nutrient Mixture F12, B27, recombinant human epidermal growth factor and basic fibroblast growth factor (39). Modifying cell culture surfaces by using $1.5 \%$ agar-coated plates (40) promotes spheroid culture formation by preventing cells attaching to their surface. According to the above conditions, the majority of tumor cells may grow and aggregate into a sphere with a diameter ranging from $20 \mu \mathrm{m}-1 \mathrm{~mm}$ (Fig. 1H). These suspension MCTS demonstrate not only numerous characteristics of solid tumor cells, but also tend to exhibit more drug-resistance to either conventional chemotherapy or monoclonal antibody drugs $(41,42)$. In addition, the suspension MCTS culture method is widely used for enriching CSC subpopulations. Under a serum-free environment, highly differentiated cells gradually die and cells with stemness potential proliferate and survive. Following several passages, CSC subpopulations may be enriched and purified (43). The enrichment of CSCs leads to increased drug resistance, accounting for the traditional view that drug penetration into the tumor spheroids may be poor. As the suspension culture model is simple and easy, it may be generated from a wide range of tumor cell types and is easily accessible for relevant experimentation, making this method compatible with high-throughput drug screening (44). However, the cells in suspension culture have no migratory movement. Furthermore, the success rate of long-term passages is low (45) and real in vivo tumor cells are not inaccessible with serum. Another important problem with drug testing is lack of defined endpoints and an accurate means for testing cell viability in 3D culture. There are no accurate cell viability assays to assess drug response throughout MCTS so far (46).

The hanging drop method is a special type of suspension culture (47). It uses a small quantity of cell suspension dropped onto a culture plate, and then the plate is inverted to create droplets, as the micro-liquid adhesion with the substrate surface is greater than its own weight. Cells will aggregate, proliferate and grow into a spheroid at the liquid-air interface of the medium drop tip (Fig. 1B). This method is relatively simple, and it has a $\sim 90 \%$ reproducibility rate for producing 1 MCTS per droplet for numerous tumor cell lines (45). At present, dedicated commercial 384-well droplet suspension plates have emerged (48). But, similar to the suspension culture, its limitations are apparent. For example, to prevent the droplet falling, the recommended drop volume is only 10-20 $\mu \mathrm{l}$. In this case, the general number of cells in MCTS is not $>500$. In addition, once the cell culture is initiated, the medium cannot be replaced and it is difficult to add the drug in the middle of culture. These inherent limitations confine the widespread use of this technique in drug discovery.

Device-assisted culture. Device-assisted suspension culture is an improvement of the static suspension culture, depending 


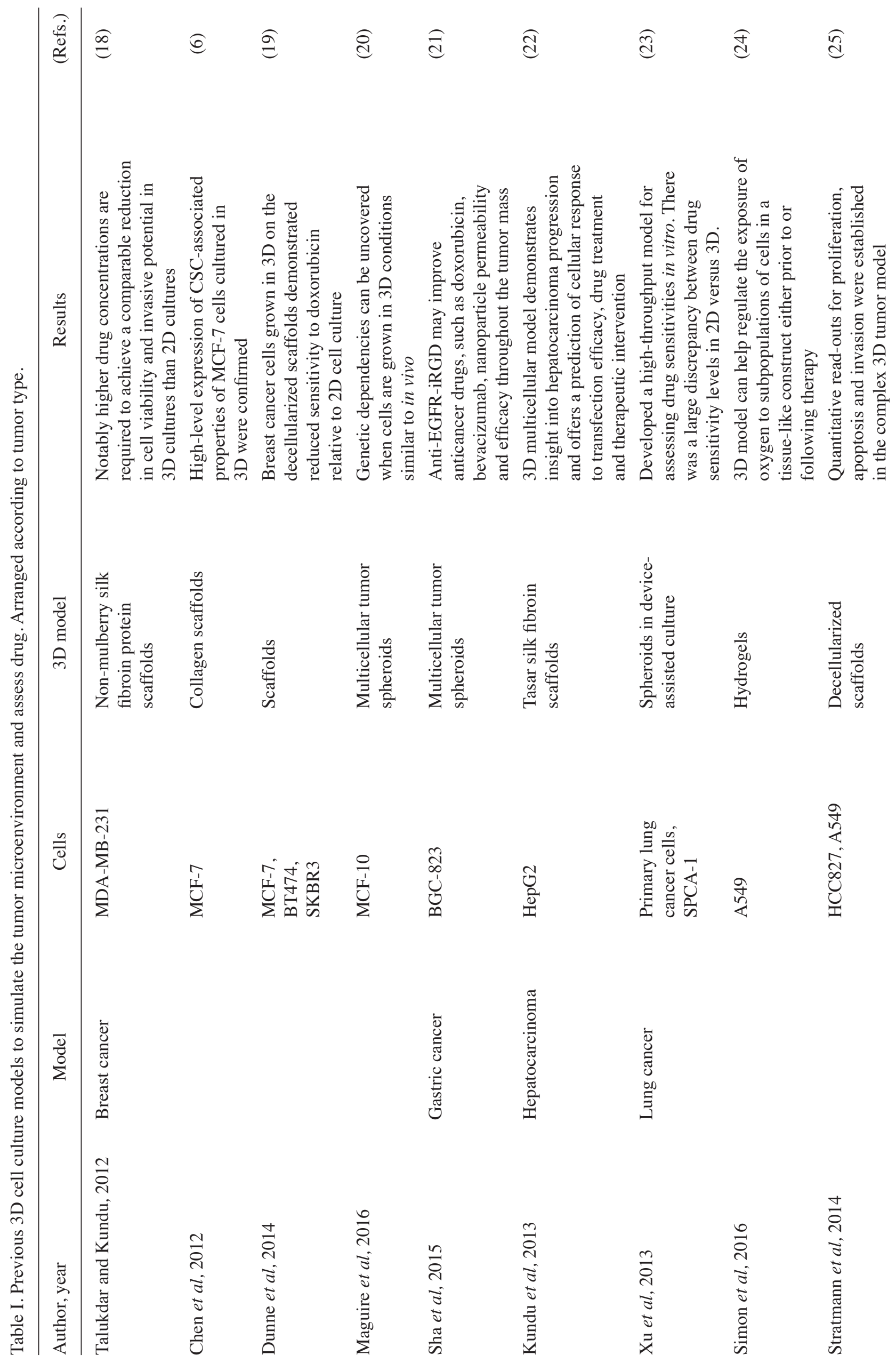




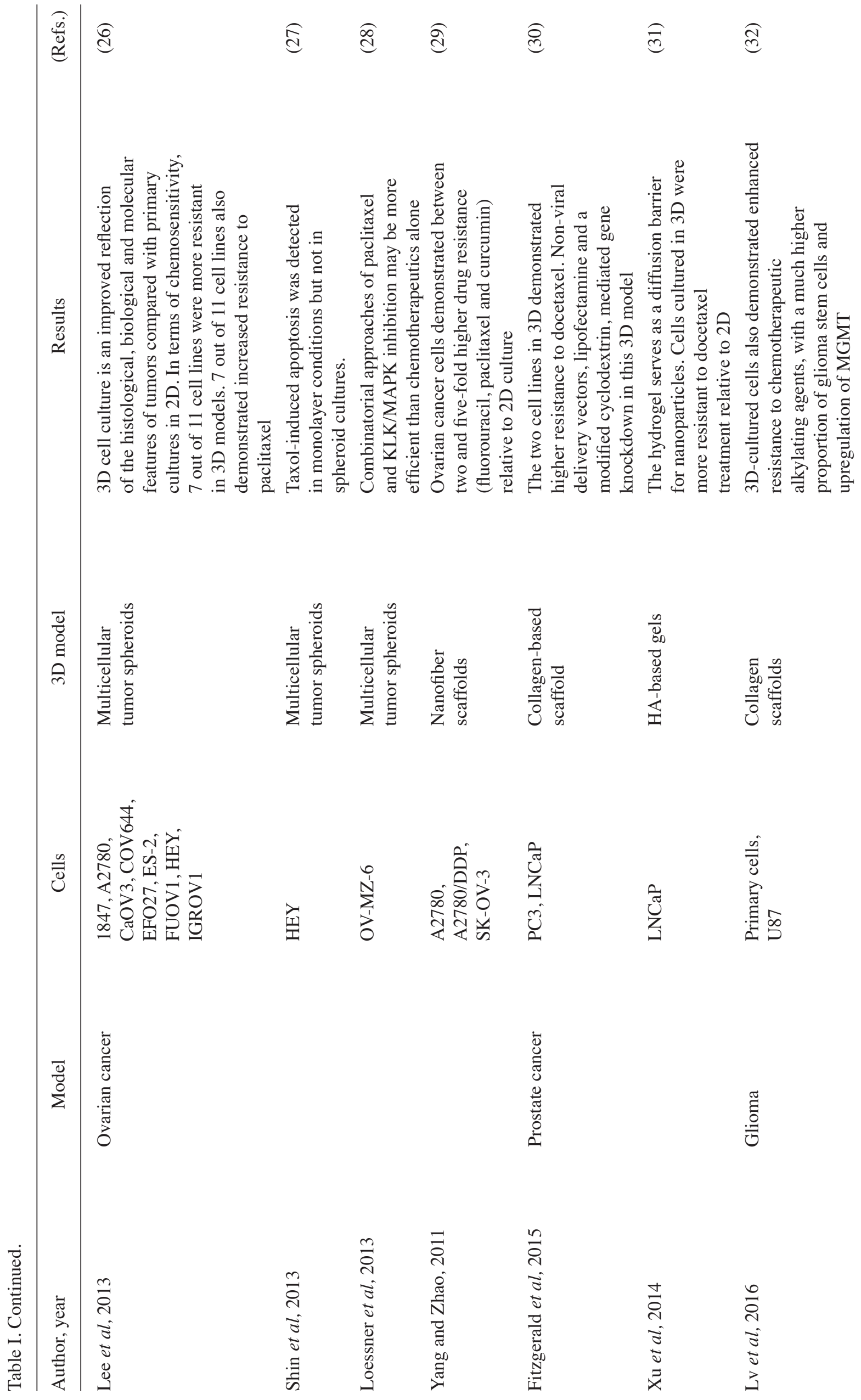




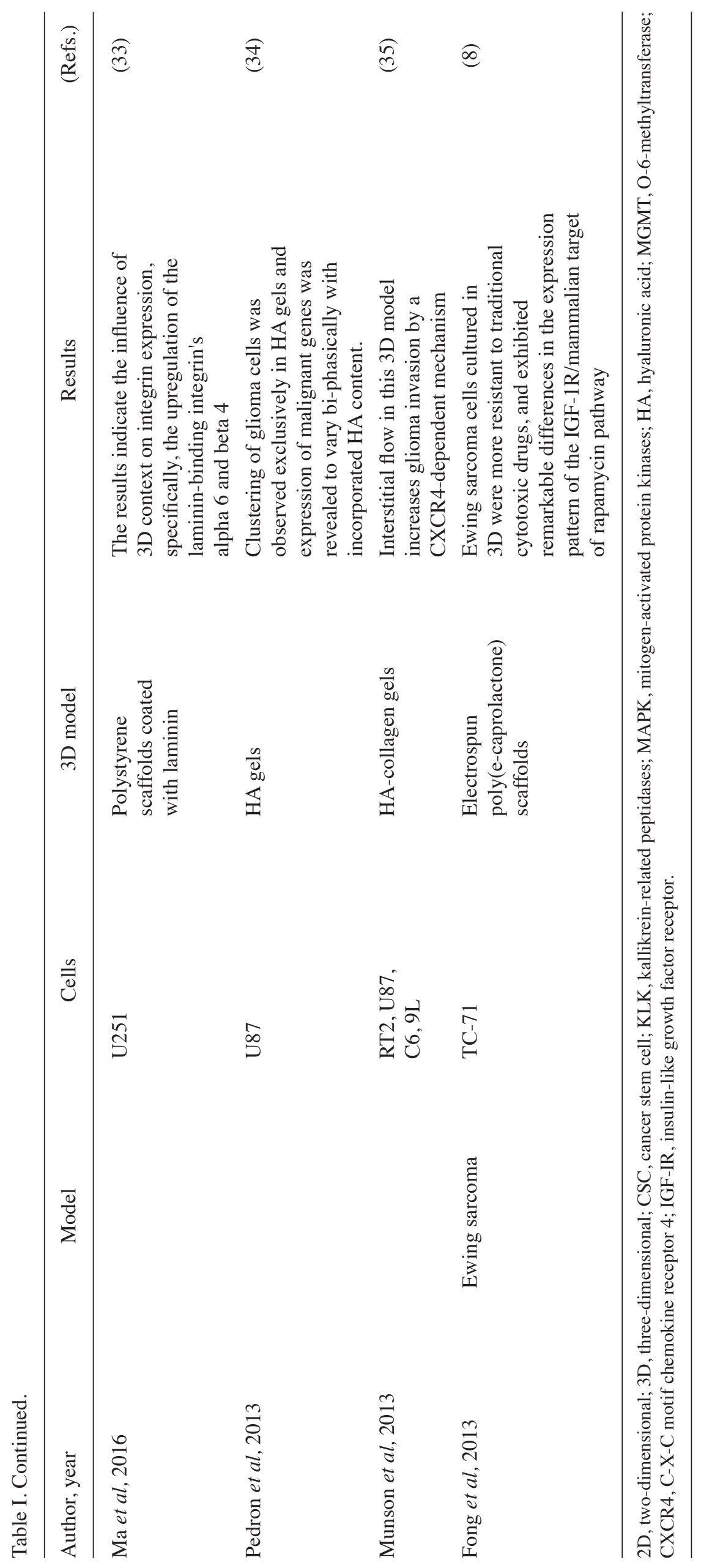




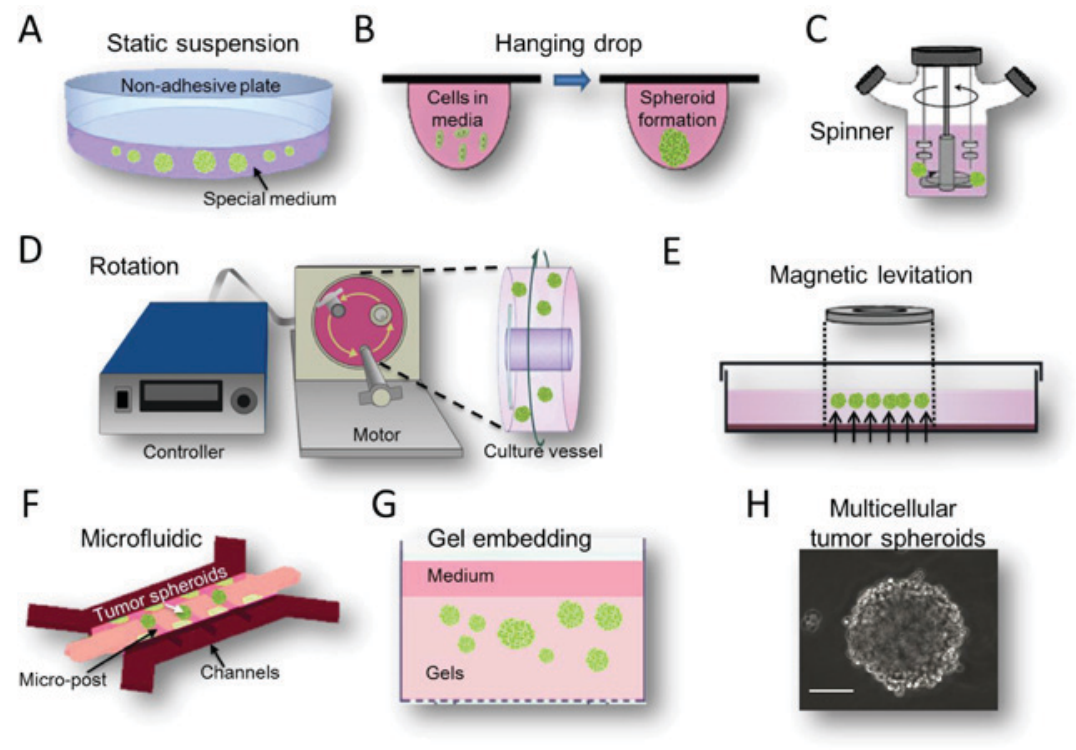

Figure 1. Methods available for MCTS formation. These methods include (A) static suspension; (B) hanging drop methods; (C) spinner bioreactor; (D) rotational bioreactor; (E) magnetic levitation; (F) microfluidic system; and (G) gel embedding. (H) A classic MCTS was observed by inverted phase contrast microscope (scale bar, $100 \mu \mathrm{m}$ ). MCTS, multicellular tumor spheroids.

on several biological devices, including magnetic levitation, spinner or rotational bioreactors and microfluidic devices. The main feature of these bioreactors is to prevent tumor cell adherence or to suspend movement, so that they may grow into MCTS. Additionally, microcarriers or microcapsules are often used in combination to increase the efficiency of cell growth and enhance the protection of the moving cells (49).

The magnetic levitation method is a novel suspension culture technology invented by n3D Bioscience (Fig. 1E). In this method are magnetized with NanoShuttle-PL during an overnight incubation and cultured on magnetic nanoparticles in dedicated plates, where they are levitated off the bottom by a magnet placed above the plate. This method does not require any artificial substrate or specialized media or equipment. Additionally, 3D cultured cells may also be picked up and transferred using magnetic tools, including the MagPen (50). Using this approach, $\mathrm{Su}$ et al (51) studied the niches and conducted a pharmaceutical synergism analysis of myeloma stem cells.

The spinner bioreactor culture method was derived from the study of tumor cells in terms of radiotherapy resistance by Durand and Sutherland (52) in 1970s. This system includes a container to hold the cells culture and an impeller or paddle stirring continuously to ensure the cells suspended and medium mixed (Fig. 1C). The liquid flow not only prevents cell adhesion, but also ensures the uniform distribution of various nutrients and oxygen. It is conducive to cellular sphere formation and metabolism. A disadvantage of this method is that the foam and fluid shear force generated by the agitation process may cause cell damage, but if the stirring speed is too low, the cells would drop and adhere easily. The rotational bioreactor culture method was adapted from the former method by the National Aeronautics and Space Administration in 1992. It is designed to use the culture container's self-rotating ability to generate microgravity (Fig. 1D), and to be used for the purpose of researching the biological characteristics of the cells in this case (53). The system is now widely used in the 3D culture of tumor cells. It may reduce damage more effectively by the fluid shear force than the former device, but it still fails to avoid mechanical damage by collision between the cells and the bioreactor wall. These bioreactor systems may produce a large number of uniform cellular spheres. Certain researchers have reported that using these two types of bioreactors may improve amplification efficiency by $8-30 x$ greater than that of the $2 \mathrm{D}$ method on the culture of stem cells $(54,55)$. Various tumor models, including hepatocellular carcinoma (56), neuroblastoma (57), breast adenocarcinoma (58) and melanoma (59) have been successfully engineered using spinner/rotational bioreactors.

Microfluidic devices, which allow spatial control over fluids in micrometer-sized channels, have become a valuable tool to further increase the physiological relevance of 3D tumor models (Fig. 1F). These devices process or manipulate micro-liquid, using microchannels with dimensions of $1-1,000 \mu \mathrm{m}$ (60). MCTS are generated within microfluidic channels. Spheroid formation may be controlled precisely in the microfluidic device. Continuous perfusion under physiological conditions during spheroid formation allows for faster formation and increased uniformly in size (61). Microfluidic platforms also allow the formation, maintenance, and testing of spheroids within a single device.

Gel embedding culture. MCTS in suspension culture lose their complicated ECM microenvironments. The solid tumor cells in vivo should not form suspended spheroids, they associate with other cells and the ECM (62). As the ECM affects cellular organization and cell function, novel 3D culture methods that incorporate ECM arguably mimic in vivo situations more accurately, as they allow for cell-ECM interactions. Gel is used as a substrate for 3D cell culture. It is a type of highly hydrophilic polymer with a soft tissue-like stiffness which aims to mimic the ECM. Tumor cells grown in the gel usually form a 
spheroid-like structure spontaneously (Fig. 1G). This structure contains not only cell-cell adhesions, but also supports contact between the cells and artificial ECM. When tumor cells are allowed to grow in gels, there is architectural support and important signaling motifs to aid in 3D cancer growth, which often leads to higher resistance to chemotherapy. For example, when human epithelial ovarian cancer cells were cultured on 3D hydrogel system as MCTS, a higher survival rate was observed following exposure to paclitaxel (63). A number of commonly used gel methods are described below.

Collagen is a widely used material in gel embedding culture (64). As a key ECM component, collagen has excellent biocompatibility for the vast majority of tumor cells. The earliest application of collagen is in tumor tissue culture. Certain tumor tissues are embedded in collagen gel for culture following cutting (diameter $\sim 1 \mathrm{~mm}$ ), and researchers have demonstrated that the tumor tissue structure and cell viability are maintained (65). Subsequently, certain researchers selected collagen for tumor tissue culture and drug sensitivity testing (66). Tumor cell culture with collagen gel was originally applied in breast cancer research. It has been revealed that the breast cancer cells in collagen gel embedding culture may form tube-like structures, which are similar to typical breast cancers in vivo (67). In CSC research, a novel colorectal cancer stem cell-enriched cell line was established by 3D culture in Collagen I (68). For drug sensitivity testing of hepatocellular carcinoma lines, cancer cells in collagen gel presented with increased drug-resistance compared with those in monolayer culture (69). With the improvement of gel technologies, complex ECM mimetic materials consisting of collagen and hyaluronic acid (HA) have been developed. These are suitable for investigating the behaviors and drug testing of glioblastoma cells (70).

Alginate is a natural polymer derived from brown seaweed. It gelates in the presence of calcium ions, and is often used for the encapsulation of various types of cells. The main advantage of alginate gel culture is that gelation may be accomplished at room temperature following addition of the cells to the polymer. It allows the cells to mix into the gel-liquid uniformly and grow nondestructively through the process of gelation. The hepatocytes in alginate gel may grow and maintain the function of albumin synthesis (71). Thus, this culture gel substrate may maintain hepatocytes function well. Breast cancer cells grown in alginate gel 3D culture form MCTS, which have stronger chemotherapy resistance compared with breast cancer cells grown in in 2D culture (72). In addition, a previous study successfully enriched multiple CSCs by culturing them in alginate gel beads (73), which suggested that alginate gel is a useful biomaterial for enriched CSCs culture.

Matrigel derives from Engelbreth-Holm-Swarm mouse tumor cell-derived basement membrane proteins which include collagen IV, laminin, entactin, perlecan, multiple cytokines and growth factors (74). It has wider commercial applications in numerous tumor cellular experiments including 3D culture and tumor invasion models. 3D cultured breast cancer cells in Matrigel exhibit a bidirectional cross-modulation of $\beta 1$-integrin and epidermal growth factor receptor signaling via the mitogen-activated protein kinase signaling pathway, but this reciprocal modulation does not occur in monolayer culture (75). These different signal pathways included transforming growth factor $\beta$ family (76) and phosphatase and tensin homolog/platelet-derived growth factor signaling network (77), which are relevant with chemotherapy and radiotherapy resistance. CSC research using Matrigel has also been performed. For example, CD271+ uveal melanoma stem cells may undergo vasculogenic mimicry in 3D Matrigel culture (78). Another previous study revealed that nicastrin, a novel typeItransmembrane glycoprotein, is associated with breast cancer stem cell properties using Matrigel culture (79). The defects of Matrigel are that it is expensive, has complex compositions and uncertain proportions between different batches of ingredients (80).

To date, novel gel techniques emerge constantly. Other new commercial gel materials include PathClear Grade Basement Membrane gel (AMS Biotechnology, Ltd., Abingdon, UK), ECM gel (Sigma-Aldrich, Merck KGaA, Darmstadt, Germany), ECL Cell Attachment Matrix (Merck KGaA) and Geltrex (Invitrogen, Thermo Fisher Scientific, Inc., Waltham, MA, USA). In the future, corresponding ECM components may be extracted from different tissues to prepare the gel according to tumor type, in order to improve mimicry of the tumor microenvironments in vivo. The potential drawback of the gel embedding culture approach is that gel lacks the cross-linked network system for the mechanical support of tumor cell growth, meaning that it is difficult to grow tumor cells diffusely.

Scaffold culture. 3D scaffolding is a product of tissue engineering developments. It may act as a surrogate for the missing ECM, representing the available space of tumor tissue, providing the physical support for cell growth, adhesion and proliferation, and causing the cells to form an appropriate spatial distribution and cell-cell or cell-ECM interaction. There are a number of differences between 2D and 3D scaffold culture. A notable comparison is that tumor cells cultured in 3D scaffolds exhibit morphological similarities to tumor cells cultured in human tumor tissues (Fig. 2). For example, glioblastoma U87 cells are fusiform, flat and epithelioid in 2D culture, but grew as small, round or ovoid cells and formed complex structures with cilia or microvilli on their surface in 3D scaffold culture (32).

In general, the procedures for preparing the scaffolds fall into one of two major categories: 1, natural polymers derived from natural polymer materials, including collagen, chitosan, glycosaminoglycans (mainly hyaluronic acid), fibroin, agarose, alginate, and starch (mainly used as additives); and 2, synthetic polymers, containing polyglycolic acid, polylactic acid, polyorthoester and their copolymers or blends, as well as the aliphatic polyester polycaprolactone (81). Natural polymers have improved biocompatibility and lower toxicity, while the artificial synthetic polymers have higher versatility, reproducibility, enhanced workability, and in a majority of cases may be processed more easily than the former, but are not bioactive (82). The processing techniques of scaffolding preparation are much more complicated than gel embedding. For providing a more well-defined architecture for tumor cell growth and improved repeatability, the porosity, mechanical strength, structural stability and degradation kinetics of the scaffold needs to be controlled. A wide range of techniques are used in generating different scaffolds, 


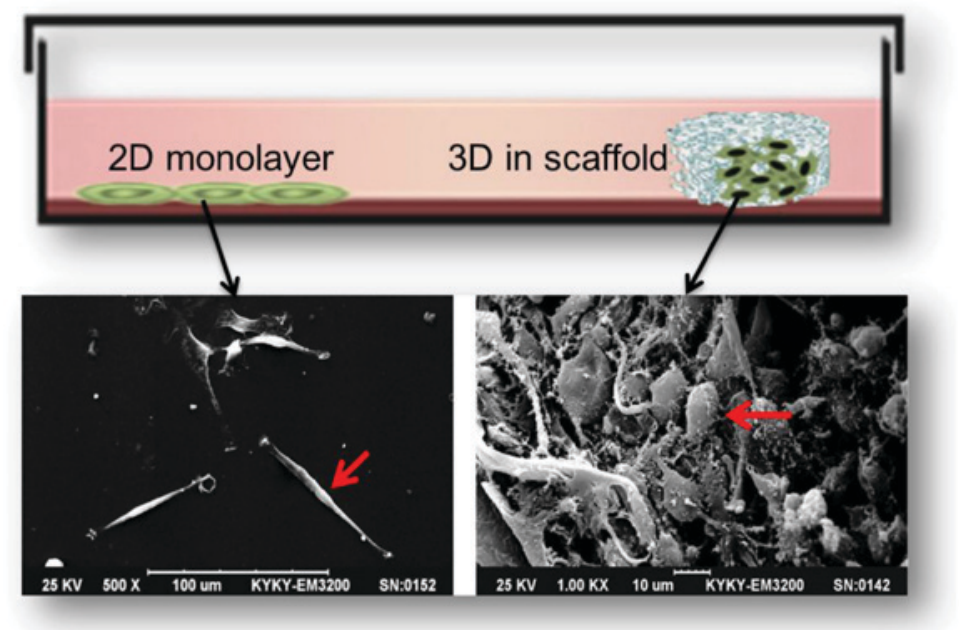

Figure 2. Comparison of tumor cells morphology between 2D and 3D scaffold culture. U87 cells in 2D (left) and 3D scaffold (right) in a scanning electron microscope image (scale bars, 100 and $10 \mu \mathrm{m}$ ). 2D, two dimensional; 3D, three dimensional.

including solvent casting/particulate leaching, freeze-drying, phase inversion, electrospinning, stereolithography, selective laser sintering, shape deposition manufacturing, 3D printing, robotic microassembly and fused deposition modeling (81). Among these techniques, solvent casting, freeze drying, phase inversion and fiber electrospinning are used a majority of the time. But the latter three techniques may become the main methods of preparing precise micro-scaffolds in the future.

A number of highly influential studies regarding 3D scaffolding culture in drug research and CSCs have been reported. Dhiman et al (7) studied the growth of breast cancer MCF-7 cells on porous chitosan scaffolds, and revealed that the response of cancer cells to tamoxifen was a 10 -fold increase in drug resistance compared with those in monolayer culture. Fong et al (8) established an in vitro 3D Ewing sarcoma model with porous 3D polycaprolactone (PCL) scaffolds. The results revealed that the tumor cells on scaffolds were not only more resistant to traditional cytotoxic drugs but also exhibited remarkable differences in the expression pattern of the insulin-like growth factor-1 receptor/mammalian target of rapamycin pathway. Furthermore, Chen et al (6) studied breast cancer cell growth on a porous collagen scaffold, and revealed that the porous scaffolds not only induced the diversification of cell morphologies but also extended cell proliferation and notably increased the expression of vascular endothelial growth factor (VEGF) and matrix metalloproteinases. Additionally, 3D collagen scaffolding upregulated a subpopulation of breast cancer stem cells, and xenografts with 3D cells formed larger tumors. These results indicate that $3 \mathrm{D}$ collagen scaffolds may provide a useful platform for anti-cancer therapeutics and CSC research. Furthermore, breast cancer stem cell expansion in PCL scaffolds (83), ovarian cancer stem cell behavior and drug resistance investigated in 3D basement membrane extract scaffolds (84) and glioma stem cells proliferating in 3D chitosan-alginate scaffolds (85) were observed in these studies, sequentially.

\section{Future trends and conclusions}

Different approaches offer different advantages and disadvantages, as summarized in Table II. Due to the inherent differences in complexity and functionality, the choice of model is usually dependent on the application. Additionally, advances in tumor cell biology, tissue engineering, biomaterials, micro-fabrication and microfluidics have enabled the rapid development of 3D tumor cell culture. Future prospects include ensuring that the main features of culture substrate are controllable and adjustable with more advanced materials and processing technologies. Depending on the different tumor types and research purposes, different biomaterials are of varying suitability for 3D culture in each specific study. For example, biomedical polymer scaffolds with low degradation rates should be manufactured for the research of bone cancer metastases. Additionally, scaffolds with added growth factors including VEGF may potentially promote the study of vascular mimicry. In addition, combining with different types of bioreactors, for example gel embedding or scaffolds used in conjunction with a micro-fluid bioreactor, may resolve the problem of cell metabolites or drugs diffusing limitedly. Furthermore, a co-culture system with two or more types of cells established under the 3D culture platform, including the co-culture of cancer cells, immune cells and endothelial cells, may mimic real tumor niches more effectively and help to clarify the effect of interactions among cancer cells, ECM and other neighboring cells (86). Automated quantification of $3 \mathrm{D}$ cultures is required in order to achieve high throughput drug screening programs (87). In addition, CSCs are novel therapeutic targets (88), and 3D tumor cell culture ought to be a useful technique in this area due to its CSC-enriching function. Greater focus on exploring appropriate ECM components in a 3D model is also critically important for monitoring tumor cell responses to exogenous cues, including growth factor activation or chemotherapy $(32,33)$.

In summary, the biological influence of the 3D microenvironment on tumor cell differentiation, progression, metastasis and chemotherapy-resistance has gained increased recognition. 3D culture, which ranges from the simple cell spheroid model to complex tissue-engineered constructs, serves an increasingly important function in tumor cell biology research. Gel embedding and scaffolds have a number of advantages in simulating the 3D structure of tumor cells in vivo compared 


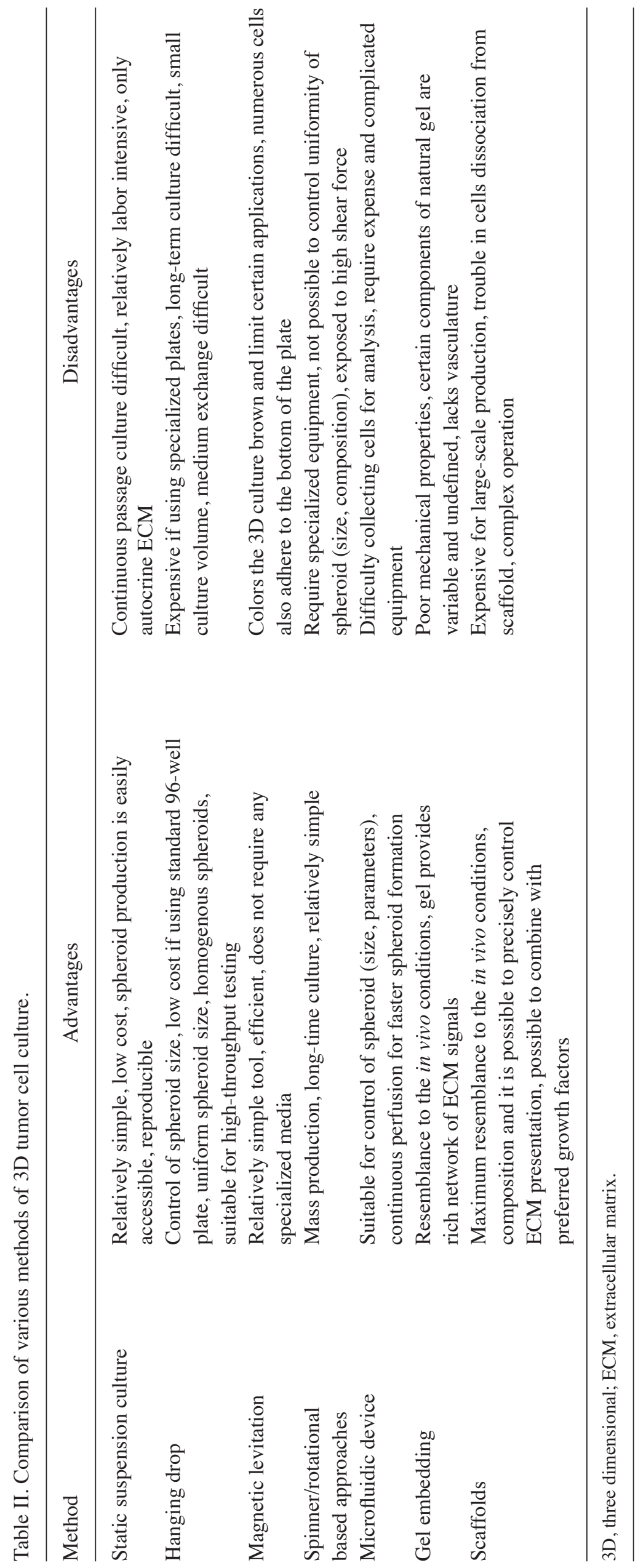


with diverse suspension culture methods, because they are more accurate at modelling the full range of microenvironmental cues, including 3D cell-cell and cell-ECM interactions. In multiple cancer research areas, particularly in the direction of drug discovery and CSC enrichment, 3D culture has unique advantages. An optimized 3D tumor model for the research of drug discovery in vitro will require cancer biologists and tissue engineers to increase efforts in this field.

\section{Acknowledgements}

The present study was supported the Key Health Project of the Nanjing Military Region (grant no. 12MA031).

\section{References}

1. Abbott A: Cell culture: Biology's new dimension. Nature 424: 870-872, 2003

2. Weigelt B, Ghajar CM and Bissell MJ: The need for complex 3D culture models to unravel novel pathways and identify accurate biomarkers in breast cancer. Adv Drug Deliv Rev 69-70: 42-51, 2014.

3. Jacks $\mathrm{T}$ and Weinberg RA: Taking the study of cancer cell survival to a new dimension. Cell 111: 923-925, 2002.

4. Breslin S and O'Driscoll L: Three-dimensional cell culture: The missing link in drug discovery. Drug Discov Today 18: 240-249, 2013.

5. Griffith LG and Swartz MA: Capturing complex 3D tissue physiology in vitro. Nat Rev Mol Cell Biol 7: 211-224, 2006.

6. Chen L, Xiao Z, Meng Y, Zhao Y, Han J, Su G, Chen B and Dai J: The enhancement of cancer stem cell properties of MCF-7 cells in 3D collagen scaffolds for modeling of cancer and anti-cancer drugs. Biomaterials 33: 1437-1444, 2012.

7. Dhiman HK, Ray AR and Panda AK: Three-dimensional chitosan scaffold-based MCF-7 cell culture for the determination of the cytotoxicity of tamoxifen. Biomaterials 26 979-986, 2005.

8. Fong EL, Lamhamedi-Cherradi SE, Burdett E, Ramamoorthy V, Lazar AJ, Kasper FK, Farach-Carson MC, Vishwamitra D, Demicco EG, Menegaz BA, et al: Modeling Ewing sarcoma tumors in vitro with 3D scaffolds. Proc Natl Acad Sci USA 110: 6500-6505, 2013.

9. Wästfelt M, Fadeel B and Henter JI: A journey of hope: Lessons learned from studies on rare diseases and orphan drugs. J Intern Med 260: 1-10, 2006.

10. Hutmacher DW: Biomaterials offer cancer research the third dimension. Nat Mater 9: 90-93, 2010.

11. Shoemaker RH: The NCI60 human tumour cell line anticancer drug screen. Nat Rev Cancer 6: 813-823, 2006.

12. Desrochers TM, Palma E and Kaplan DL: Tissue-engineered kidney disease models. Adv Drug Deliv Rev 69-70: 67-80, 2014

13. Cree IA, Glaysher S and Harvey AL: Efficacy of anti-cancer agents in cell lines versus human primary tumour tissue. Curr Opin Pharmacol 10: 375-379, 2010.

14. Uchida Y, Tanaka S, Aihara A, Adikrisna R, Yoshitake K, Matsumura S, Mitsunori Y, Murakata A, Noguchi N, Irie T, et al: Analogy between sphere forming ability and stemness of human hepatoma cells. Oncol Rep 24: 1147-1151, 2010 .

15. Stevens JL and Baker TK: The future of drug safety testing: Expanding the view and narrowing the focus. Drug Discov Today 14: 162-167, 2009

16. Huh D, Matthews BD, Mammoto A, Montoya-Zavala M, Hsin HY and Ingber DE: Reconstituting organ-level lung functions on a chip. Science 328: 1662-1668, 2010.

17. Russell WMS and Burch RL: The principles of humane experimental technique. Methuen, London, 1959.

18. Talukdar S and Kundu SC: A non-mulberry silk fibroin protein based 3D in vitro tumor model for evaluation of anticancer drug activity. Adv Funct Mat 22: 4778-4788, 2012.

19. Dunne LW, Huang Z, Meng W, Fan X, Zhang N, Zhang Q and An Z: Human decellularized adipose tissue scaffold as a model for breast cancer cell growth and drug treatments. Biomaterials 35: 4940-4949, 2014.
20. Maguire SL, Peck B, Wai PT, Campbell J, Barker H, Gulati A, Daley F, Vyse S, Huang P, Lord CJ, et al: Three-dimensional modelling identifies novel genetic dependencies associated with breast cancer progression in the isogenic MCF10 model. J Pathol 240: 315-328, 2016.

21. Sha H, Zou Z, Xin K, Bian X, Cai X, Lu W, Chen J, Chen G, Huang L, Blair AM, et al: Tumor-penetrating peptide fused EGFR single-domain antibody enhances cancer drug penetration into 3D multicellular spheroids and facilitates effective gastric cancer therapy. J Control Release 200: 188-200, 2015.

22. Kundu B, Saha P, Datta K and Kundu SC: A silk fibroin based hepatocarcinoma model and the assessment of the drug response in hyaluronan-binding protein 1 overexpressed HepG2 cells. Biomaterials 34: 9462-9474, 2013.

23. Xu Z, Gao Y, Hao Y, Li E, Wang Y, Zhang J, Wang W, Gao Z and Wang Q: Application of a microfluidic chip-based 3D co-culture to test drug sensitivity for individualized treatment of lung cancer. Biomaterials 34: 4109-4117, 2013.

24. Simon KA, Mosadegh B, Minn KT, Lockett MR, Mohammady MR, Boucher DM, Hall AB, Hillier SM, Udagawa T, Eustace BK and Whitesides GM: Metabolic response of lung cancer cells to radiation in a paper-based 3D cell culture system. Biomaterials 95: 47-59, 2016.

25. Stratmann AT, Fecher D, Wangorsch G, Göttlich C, Walles T, Walles H, Dandekar T, Dandekar G and Nietzer SL: Establishment of a human 3D lung cancer model based on a biological tissue matrix combined with a Boolean in silico model. Mol Oncol 8: 351-365, 2014.

26. Lee JM, Mhawech-Fauceglia P, Lee N, Parsanian LC, Lin YG, Gayther SA and Lawrenson K: A three-dimensional microenvironment alters protein expression and chemosensitivity of epithelial ovarian cancer cells in vitro. Lab Invest 93: 528-542, 2013.

27. Shin CS, Kwak B, Han B and Park K: Development of an in vitro 3D tumor model to study therapeutic efficiency of an anticancer drug. Mol Pharm 10: 2167-2175, 2013.

28. Loessner D, Rizzi SC, Stok KS, Fuehrmann T, Hollier B, Magdolen V, Hutmacher DW and Clements JA: A bioengineered 3D ovarian cancer model for the assessment of peptidase-mediated enhancement of spheroid growth and intraperitoneal spread. Biomaterials 34: 7389-7400, 2013.

29. Yang $Z$ and Zhao X: A 3D model of ovarian cancer cell lines on peptide nanofiber scaffold to explore the cell-scaffold interaction and chemotherapeutic resistance of anticancer drugs. Int J Nanomedicine 6: 303-310, 2011.

30. Fitzgerald KA, Guo J, Tierney EG, Curtin CM, Malhotra M, Darcy R, O'Brien FJ and O'Driscoll CM: The use of collagen-based scaffolds to simulate prostate cancer bone metastases with potential for evaluating delivery of nanoparticulate gene therapeutics. Biomaterials 66: 53-66, 2015.

31. Xu X, Sabanayagam CR, Harrington DA, Farach-Carson MC and Jia X: A hydrogel-based tumor model for the evaluation of nanoparticle-based cancer therapeutics. Biomaterials 35: 3319-3330, 2014.

32. Lv D, Yu SC, Ping YF, Wu H, Zhao X, Zhang H, Cui Y, Chen B, Zhang X, Dai J, et al: A three-dimensional collagen scaffold cell culture system for screening anti-glioma therapeutics. Oncotarget 7: 56904-56914, 2016.

33. Ma NK, Lim JK, Leong MF, Sandanaraj E, Ang BT, Tang C and Wan AC: Collaboration of 3D context and extracellular matrix in the development of glioma stemness in a 3D model. Biomaterials 78: $62-73,2016$

34. Pedron S, Becka E and Harley BA: Regulation of glioma cell phenotype in 3D matrices by hyaluronic acid. Biomaterials 34: 7408-7417, 2013.

35. Munson JM, Bellamkonda RV and Swartz MA: Interstitial flow in a 3D microenvironment increases glioma invasion by a CXCR4-dependent mechanism. Cancer Res 73: 1536-1546, 2013.

36. Fennema E, Rivron N, Rouwkema J, van Blitterswijk C and de Boer J: Spheroid culture as a tool for creating 3D complex tissues. Trends Biotechnol 31: 108-115, 2013.

37. Friedrich J, Seidel C, Ebner R and Kunz-Schughart LA: Spheroid-based drug screen: Considerations and practical approach. Nat Protoc 4: 309-324, 2009.

38. Reynolds BA and Weiss S: Generation of neurons and astrocytes from isolated cells of the adult mammalian central nervous system. Science 255: 1707-1710, 1992.

39. Yu SC, Ping YF, Yi L, Zhou ZH, Chen JH, Yao XH, Gao L, Wang JM and Bian XW: Isolation and characterization of cancer stem cells from a human glioblastoma cell line U87. Cancer Lett 265: 124-134, 2008. 
40. Yuhas JM, Li AP, Martinez AO and Ladman AJ: A simplified method for production and growth of multicellular tumor spheroids. Cancer Res 37: 3639-3643, 1977.

41. Lawlor ER, Scheel C, Irving J and Sorensen PH: Anchorage-independent multi-cellular spheroids as an in vitro model of growth signaling in Ewing tumors. Oncogene 21: 307-318, 2002.

42. Lin RZ and Chang HY: Recent advances in three-dimensional multicellularspheroidcultureforbiomedical research.Biotechnol J 3: 1172-1184, 2008.

43. Pang R, Law WL, Chu AC, Poon JT, Lam CS, Chow AK, Ng L, Cheung LW, Lan XR, Lan HY, et al: A subpopulation of CD26+ cancer stem cells with metastatic capacity in human colorectal cancer. Cell Stem Cell 6: 603-615, 2010.

44. Ivascu A and Kubbies M: Rapid generation of single-tumor spheroids for high-throughput cell function and toxicity analysis. J Biomol Screen 11: 922-932, 2006.

45. Louis SA, Rietze RL, Deleyrolle L, Wagey RE, Thomas TE, Eaves AC and Reynolds BA: Enumeration of neural stem and progenitor cells in the neural colony-forming cell assay. Stem Cells 26: 988-996, 2008.

46. Ng KW, Leong DT and Hutmacher DW: The challenge to measure cell proliferation in two and three dimensions. Tissue Eng 11: 182-191, 2005.

47. Kelm JM, Timmins NE, Brown CJ, Fussenegger $M$ and Nielsen LK: Method for generation of homogeneous multicellular tumor spheroids applicable to a wide variety of cell types. Biotechnol Bioeng 83: 173-180, 2003.

48. Tung YC, Hsiao AY, Allen SG, Torisawa YS, Ho M and Takayama S: High-throughput 3D spheroid culture and drug testing using a 384 hanging drop array. Analyst 136: 473-478, 2011.

49. Zanetta M, Quirici N, Demarosi F, Tanzi MC, Rimondini L and Farè S: Ability of polyurethane foams to support cell proliferation and the differentiation of MSCs into osteoblasts. Acta Biomater 5: 1126-1136, 2009.

50. Souza GR, Molina JR, Raphael RM, Ozawa MG, Stark DJ, Levin CS, Bronk LF, Ananta JS, Mandelin J, Georgescu MM, et al: Three-dimensional tissue culture based on magnetic cell levitation. Nat Nanotechnol 5: 291-296, 2010

51. Su J, Zhang L, Zhang W, Choi DS, Wen J, Jiang B, Chang CC and Zhou X: Targeting the biophysical properties of the myeloma initiating cell niches: A pharmaceutical synergism analysis using multi-scale agent-based modeling. PLoS One 9: e85059, 2014.

52. Durand RE and Sutherland RM: Effects of intercellular contact on repair of radiation damage. Exp Cell Res 71: 75-80, 1972.

53. Goodwin TJ, Prewett TL, Wolf DA and Spaulding GF: Reduced shear stress: A major component in the ability of mammalian tissues to form three-dimensional assemblies in simulated microgravity. J Cell Biochem 51: 301-311, 1993.

54. Chen X, Xu H, Wan C, McCaigue M and Li G: Bioreactor expansion of human adult bone marrow-derived mesenchymal stem cells. Stem Cells 24: 2052-2059, 2006

55. Luni C, Feldman HC, Pozzobon M, De Coppi P, Meinhart CD and Elvassore N: Microliter-bioreactor array with buoyancy-driven stirring for human hematopoietic stem cell culture. Biomicrofluidics 4: pii: 034105, 2010.

56. Chang TT and Hughes-Fulford M: Monolayer and spheroid culture of human liver hepatocellular carcinoma cell line cells demonstrate distinct global gene expression patterns and functional phenotypes. Tissue Eng Part A 15: 559-567, 2009.

57. Redden RA and Doolin EJ: Microgravity assay of neuroblastoma: In vitro aggregation kinetics and organoid morphology correlate with MYCN expression. In Vitro Cell Dev Biol Anim 47: 312-317, 2011.

58. Kaur P, Ward B, Saha B, Young L, Groshen S, Techy G, Lu Y, Atkinson R, Taylor CR, Ingram M and Imam SA: Human breast cancer histoid: An in vitro 3-dimensional co-culture model that mimics breast cancer tissue. J Histochem Cytochem 59: 1087-1100, 2011.

59. Marrero B, Messina JL and Heller R: Generation of a tumor spheroid in a microgravity environment as a 3D model of melanoma. In Vitro Cell Dev Biol Anim 45: 523-534, 2009.

60. Zhang Z and Nagrath S: Microfluidics and cancer: Are we there yet? Biomed Microdevices 15: 595-609, 2013.

61. Mehta G, Hsiao AY, Ingram M, Luker GD and Takayama S: Opportunities and challenges for use of tumor spheroids as models to test drug delivery and efficacy. J Control Release 164: 192-204, 2012.
62. Gill BJ and West JL: Modeling the tumor extracellular matrix: Tissue engineering tools repurposed towards new frontiers in cancer biology. J Biomech 47: 1969-1978, 2014.

63. Loessner D, Stok KS, Lutolf MP, Hutmacher DW, Clements JA and Rizzi SC: Bioengineered 3D platform to explore cell-ECM interactions and drug resistance of epithelial ovarian cancer cells. Biomaterials 31: 8494-8506, 2010.

64. Nirmalanandhan VS, Duren A, Hendricks P, Vielhauer G and Sittampalam GS: Activity of anticancer agents in a three-dimensional cell culture model. Assay Drug Dev Technol 8: 581-590, 2010.

65. Freeman AE and Hoffman RM: In vivo-like growth of human tumors in vitro. Proc Natl Acad Sci USA 83: 2694-2698, 1986.

66. Takamura Y, Kobayashi H, Taguchi T, Motomura K, Inaji H and Noguchi S: Prediction of chemotherapeutic response by collagen gel droplet embedded culture-drug sensitivity test in human breast cancers. Int J Cancer 98: 450-455, 2002.

67. Yang J,Richards J,Bowman P,Guzman R,Enami J,McCormick K, Hamamoto S, Pitelka D and Nandi S: Sustained growth and three-dimensional organization of primary mammary tumor epithelial cells embedded in collagen gels. Proc Natl Acad Sci USA 76: 3401-3405, 1979.

68. Rowehl RA, Burke S, Bialkowska AB, Pettet DW III, Rowehl L, Li E, Antoniou E, Zhang Y, Bergamaschi R, Shroyer KR, et al: Establishment of highly tumorigenic human colorectal cancer cell line (CR4) with properties of putative cancer stem cells. PLoS One 9: e99091, 2014.

69. Yip D and Cho CH: A multicellular 3D heterospheroid model of liver tumor and stromal cells in collagen gel for anti-cancer drug testing. Biochem Biophys Res Commun 433: 327-332, 2013.

70. Rao SS, Dejesus J, Short AR, Otero JJ, Sarkar A and Winter JO: Glioblastoma behaviors in three-dimensional collagen-hyaluronan composite hydrogels. ACS Appl Mater Interfaces 5: 9276-9284, 2013

71. Dvir-Ginzberg M, Gamlieli-Bonshtein I, Agbaria R and Cohen S: Liver tissue engineering within alginate scaffolds: Effects of cell-seeding density on hepatocyte viability, morphology, and function. Tissue Eng 9: 757-766, 2003.

72. Zhang X, Wang W, Yu W, Xie Y, Zhang Y and MaX: Development of an in vitro multicellular tumor spheroid model using microencapsulation and its application in anticancer drug screening and testing. Biotechnol Prog 21: 1289-1296, 2005.

73. Xu XX, Liu C, Liu Y, Yang L, Li N, Guo X, Sun GW and Ma XJ: Enrichment of cancer stem cell-like cells by culture in alginate gel beads. J Biotechnol 177: 1-12, 2014.

74. Kleinman HK and Martin GR: Matrigel: Basement membrane matrix with biological activity. Semin Cancer Biol 15: 378-386, 2005.

75. Wang F, Weaver VM, Petersen OW, Larabell CA, Dedhar S, Briand P, Lupu R and Bissell MJ: Reciprocal interactions between betal-integrin and epidermal growth factor receptor in three-dimensional basement membrane breast cultures: A different perspective in epithelial biology. Proc Natl Acad Sci USA 95: 14821-14826, 1998.

76. Ampuja M, Jokimäki R, Juuti-Uusitalo K, Rodriguez-Martinez A, Alarmo EL and Kallioniemi A: BMP4 inhibits the proliferation of breast cancer cells and induces an MMP-dependent migratory phenotype in MDA-MB-231 cells in 3D environment. BMC Cancer 13: 429, 2013.

77. Christensen M, Najy AJ, Snyder M, Movilla LS and Kim HR: A critical role of the PTEN/PDGF signaling network for the regulation of radiosensitivity in adenocarcinoma of the prostate. Int $\mathrm{J}$ Radiat Oncol Biol Phys 88: 151-158, 2014.

78. Valyi-Nagy K, Kormos B, Ali M, Shukla D and Valyi-Nagy T: Stem cell marker CD271 is expressed by vasculogenic mimicry-forming uveal melanoma cells in three-dimensional cultures. Mol Vis 18: 588-592, 2012

79. Lombardo Y, Filipović A, Molyneux G, Periyasamy M, Giamas G, Hu Y, Trivedi PS, Wang J, Yagüe E, Michel L and Coombes RC: Nicastrin regulates breast cancer stem cell properties and tumor growth in vitro and in vivo. Proc Natl Acad Sci USA 109: 16558-16563, 2012.

80. Sodunke TR,Turner KK, Caldwell SA,McBride KW, Reginato MJ and Noh HM: Micropatterns of Matrigel for three-dimensional epithelial cultures. Biomaterials 28: 4006-4016, 2007

81. Carletti E, Motta A and Migliaresi C: Scaffolds for tissue engineering and 3D cell culture. Methods Mol Biol 695: 17-39, 2011.

82. Liu X, Holzwarth JM and Ma PX: Functionalized synthetic biodegradable polymer scaffolds for tissue engineering. Macromol Biosci 12: 911-919, 2012. 
83. Feng S, Duan X, Lo PK, Liu S, Liu X, Chen H and Wang Q Expansion of breast cancer stem cells with fibrous scaffolds. Integr Biol (Camb) 5: 768-777, 2013.

84. Chen J, Wang J, Zhang Y, Chen D, Yang C, Kai C, Wang X, Shi F and Dou J: Observation of ovarian cancer stem cell behavior and investigation of potential mechanisms of drug resistance in three-dimensional cell culture. J Biosci Bioeng 118: 214-222, 2014.

85. Kievit FM, Florczyk SJ, Leung MC, Wang K, Wu JD, Silber JR, Ellenbogen RG, Lee JS and Zhang M: Proliferation and enrichment of CD133(+) glioblastoma cancer stem cells on 3D chitosan-alginate scaffolds. Biomaterials 35: 9137-9143, 2014.
86. Amann A, Zwierzina M, Gamerith G, Bitsche M, Huber JM, Vogel GF, Blumer M, Koeck S, Pechriggl EJ, Kelm JM, et al: Development of an innovative 3D cell culture system to study tumour-stroma interactions in non-small cell lung cancer cells. PLoS One 9: e92511, 2014.

87. Hoque MT, Windus LC, Lovitt CJ and Avery VM: PCaAnalyser: A 2D-image analysis based module for effective determination of prostate cancer progression in 3D culture. PLoS One 8: e79865, 2013.

88. Ciurea ME, Georgescu AM, Purcaru SO, Artene SA, Emami GH, Boldeanu MV, Tache DE and Dricu A: Cancer stem cells: Biological functions and therapeutically targeting. Int J Mol Sci 15: 8169-8185, 2014. 